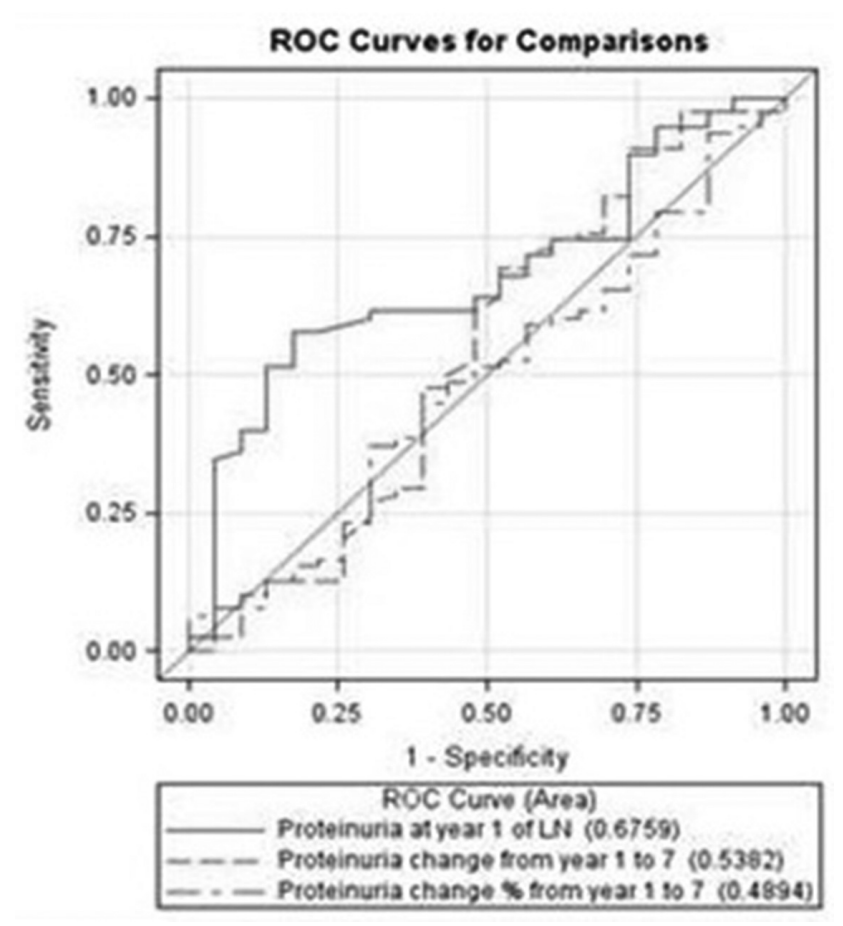

Abstract 445 Figure 1 ROC curve of proteinuria at 1 year, absolute change and percentage of change between year 1 and 7 .

The predictive power of three lab tests at 1 year after $\mathrm{WN}$ to the renal outcome at 7 th year after $L N$

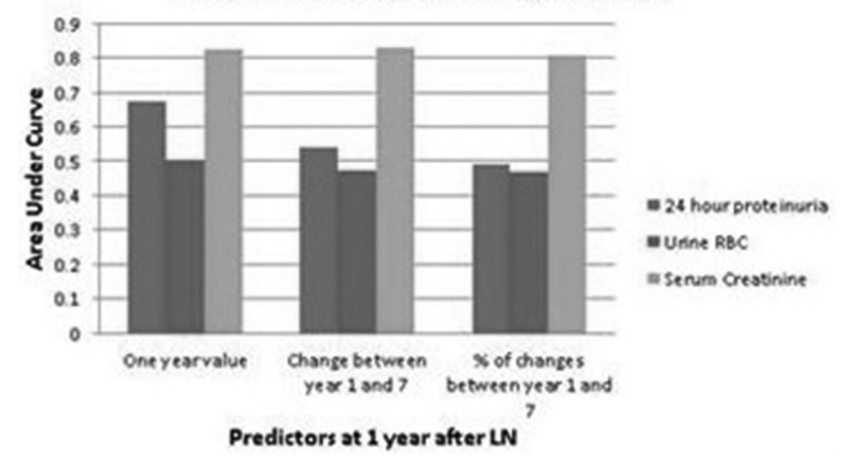

Abstract 445 Figure 2

predictive benefit while $\mathrm{Cr}$ at 1 year predicted long-term renal outcome with an AUC of 0.82 (Figure 2).

Conclusions Proteinuria of $0.6 \mathrm{~g} / \mathrm{d}$ at 1 year and $\mathrm{Cr}$ at 1 year post-LN diagnosis best predicted good long-term renal outcome. uRBCs did not offer any prognostic benefit.

\section{RELATION OF VITAMIN D LEVELS IN SLE NUMBER OF SEVERE FLARES}

${ }^{1} \mathrm{~A}$ Marinho, ${ }^{2} \mathrm{D}$ Boleixa, ${ }^{2} \mathrm{C}$ Carvalho, ${ }^{2} \mathrm{~A}$ Bettencourt, ${ }^{2} \mathrm{~B}$ Martins da Silva, ${ }^{1} \mathrm{C}$ Vasconcelos. ${ }^{1}$ Centro Hospitalar Do Porto, Internal Medicinw, Porto, Portugal; ${ }^{2}$ ICBAS, Immunogenetics, Oporto, Portugal

10.1136/lupus-2017-000215.446
Background and aims The aim of this study was to evaluate retrospective data of Vitamin D levels in SLE patients, at the beginning of the disease and mean values during 10-years follow-up, and correlate them with severe flares frequency.

Methods We selected, from a cohort of 675 SLE patients, 112 patients who had baseline Vitamin D levels at SLE diagnosis and 68 patients with at least three evaluations of Vitamin D levels during the last 10 -years follow-up. The number of severe flares (defined by the SELENA-SLEDAI flare composite index) was required for all patients. We correlated the baseline Vitamin D levels with severe flare number and with patients with three or more and less than three severe flares. We also correlated severe flares with mean Vitamin $D$ value in the last 10-years follow-up.

Results We observed a higher number of flares in patients with low disease baseline Vitamin D levels $(p=0.045)$. We also observed that patients with three or more flares have significant lower baseline Vitamin D levels $(p=0.004)$. The mean Vitamin D levels in the previous 10-years of disease, were lower in patients with more severe flares, although not significant $(p=0.178)$. However, if we divide them in two subgroups (patients with three or more and less than three severe flares), the difference is significant $(\mathrm{p}=0.044)$.

Conclusions Vitamin D levels at the beginning of the disease and the vitamin D burden during disease are related to the number of severe flares and so resulting in more aggressive phenotypes.

\section{IMPROVING THE QUALITY OF CARE IN SYSTEMIC LUPUS ERYTHEMATOSUS (SLE) THROUGH TIME-STRUCTURED, INFORMATION TECHNOLOGY-ENHANCED, QUALITY IMPROVEMENT INDICATOR-DRIVEN PATIENT MANAGEMENT}

${ }^{1} \mathrm{R}$ Quinet, ${ }^{1}$ W Davis, ${ }^{2} \mathrm{D}$ Wray, ${ }^{1} \mathrm{~T}$ Hilbun, ${ }^{1} \mathrm{M}$ Budziakowska, ${ }^{1} \mathrm{~F}$ Migliore*. ${ }^{2}$ Ochsner Health System, Rheumatology, New Orleans, USA; ${ }^{2}$ Twine Clinical Consulting LLC, Healthcare Quality Improvement, Park City, USA

\subsection{6/lupus-2017-000215.447}

Background and aims Gaps exist in SLE patient care at Ochsner Health System (Ochsner) related to both A) monitoring and management of comorbidities and treatment-related toxicities and, B) monitoring and management of disease activity. The uncovered gaps suggested a lack of well-defined systems of care in SLE within Ochsner that lead to a "looser" overall management of SLE patients than is optimal. Our hypothesis was that a more time-structured, IT-enhanced, and QI indicator-driven approach to SLE patient management would translate into a more frequent, more comprehensive, and guidelineadherent interaction with the patient (i.e. "tighter" management). This "tighter" management, we hypothesised, would manifest as improved patient outcomes.

Methods In order to prompt "tighter" management, we implemented the following interventional modalities:

- Lupus Management Module: An SLE-specific management dashboard programmatically embedded into the Epic EHR system in use at Ochsner. The dashboard incorporates SLEmanagement-specific reminders, alerts, historical test result tracking, and customised assessment (SLEDAI, SLICC) programming. 


\section{Abstract 447 Table 1}

\begin{tabular}{|c|c|c|c|c|}
\hline \multicolumn{2}{|c|}{ Physician-Behavioral Metrics } & \multirow{2}{*}{ 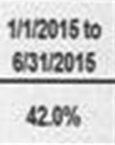 } & \multirow{2}{*}{$\begin{array}{l}\begin{array}{l}1 / 12016 \text { to } \\
6 / 312016\end{array} \\
48.7 \%\end{array}$} & \multirow{2}{*}{$\begin{array}{c}\text { 2-Test for Proportions (Independent Groups } \\
\text { Statistically Significant Diflerence } \\
95 \% \text { confidence }(0=.0318)\end{array}$} \\
\hline Metric 1 & Rate of SLE patents having office visits at least $1 \times 16$ months. & & & \\
\hline Metric 2 & Rate of SLEDAl application at least $1 \times 16$ months. & $138 \%$ & $18.7 \%$ & $\begin{array}{l}\text { Statistically Significant Difterence } \\
95 \% \text { confidence }(p=0341)\end{array}$ \\
\hline Wetric 3 & $\begin{array}{l}\text { Rate of administration of influenza vaccination in the last } 12 \\
\text { months. }\end{array}$ & $13.9 \%$ & $18.0 \%$ & $\begin{array}{l}\text { Stafistically Significant Difterence } \\
90 \% \text { confidence }(\rho=.0760)\end{array}$ \\
\hline Metric 4 & Rate of administration of pneumococcal vaccination (ever) & $30.4 \%$ & $31.5 \%$ & Not Statsstcally Significant \\
\hline Metric 5 & Rate of patents with prednisone dose $>7.5 \mathrm{mg} / \mathrm{day}$. & $11.5 \%$ & $7.4 \%$ & $\begin{array}{l}\text { Staststically Significant Difference } \\
95 \% \text { confidence }(p=0254)\end{array}$ \\
\hline
\end{tabular}

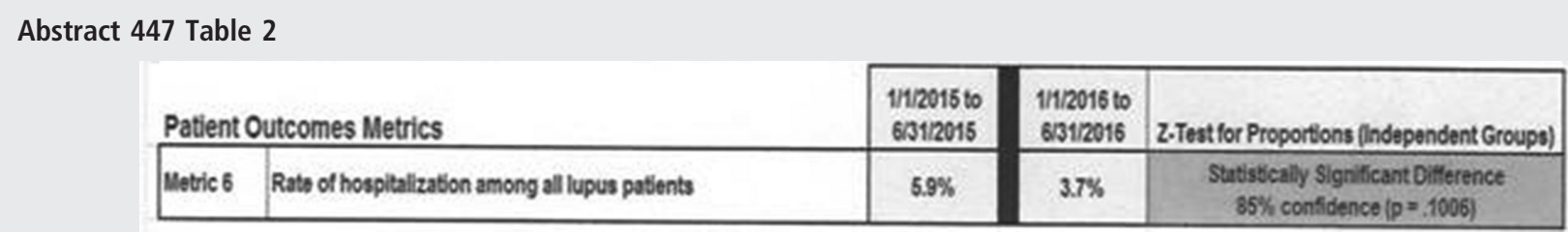

- Patient Campaigning: Identification of patients who are due for various SLE-specific testing or management activities and proactive contact in order to prompt an office visit.

Results We demonstrated a "tighter" management of SLE patients through statistically significant improvement in the rate of key SLE management behaviours (95\% CI).

"Tighter" management, in turn, prompted statistically significant improvement in hospitalisation $(85 \% \mathrm{CI})$.

Conclusions Time-structured, IT-enhanced, and QI indicatordriven interventional modalities prompted a more frequent, more comprehensive, and guideline-adherent point of care interaction with SLE patients (i.e. "tighter" management). "Tighter" management manifested as improved patient outcomes in the form of a diminished rate of hospitalisation among SLE patients.

\section{BONE MARROW MEGAKARYOCYTES MAY PREDICT THERAPEUTIC RESPONSE OF SEVERE THROMBOCYTOPENIA IN PATIENTS WITH SYSTEMIC LUPUS ERYTHEMATOSUS}

W Mo*, L Zhao, X Zhang. Beijing peking union medical college hospital, rheumatology, Beijing, China

\subsection{6/lupus-2017-000215.448}

Background and aims To analyse the predictive value of megakaryocyte counts in bone marrow (BM-MK) for determining the therapeutic response of severe thrombocytopenia (TP) in patients with systemic lupus erythematosus (SLE).

Methods Thirty-five patients with SLE with severe TP (platelet count $\leq 50 \times 109 / 1)$ from the Peking Union Medical College Hospital admitted between 2007 and 2014 with appreciable bone marrow aspiration results were analysed retrospectively. The associations between therapeutic response and clinical manifestations, laboratory findings including BM-MK counts, were evaluated.

Results Seventeen (49\%) and 8 (23\%) patients achieved a complete response $(\mathrm{CR})$ and a partial response (PR), respectively, and 10 had no response (NR). The BM-MK counts in each group were $102 \pm 25(0-322), 136 \pm 48$ (2-419), and 28 $\pm 12(0-105)$ per slide, respectively. Significant differences were observed in the counts of BM-MK between patients who achieved a clinical response $(\mathrm{CR}+\mathrm{PR})$ and those who did not $(\mathrm{NR} ; \mathrm{p}=0.007)$. Patients in the NR group exhibited fewer BM-MK compared with those in the $\mathrm{CR}$ and $\mathrm{PR}$ groups $(\mathrm{p}=0.017$ and $\mathrm{p}=0.006$, respectively). A receiver-operation characteristic analysis identified that a cutoff value of BM-MK counts at 20 performed pretty well in discriminating patients with differential responses to immunotherapy, with sensitivity and specificity and area under the curve of $88 \%, 70 \%$, and 0.798 , respectively.

Conclusions BM-MK count may serve as a good predicting factor for immunotherapeutic response in patients with SLE with severe TP. Patients with BM-MK counts $<20$ per slide tend to exhibit poor clinical response.

\section{EFFECT OF DISEASE REMISSION ON ORGAN DAMAGE AND QUALITY OF LIFE IN CHINESE PATIENTS WITH SYSTEMIC LUPUS ERYTHEMATOSUS}

${ }^{1} \mathrm{CC}$ Mok*, ${ }^{2} \mathrm{SM}$ Tse, ${ }^{2} \mathrm{KL}$ Chan, ${ }^{2} \mathrm{LY}$ Ho. ${ }^{1}$ Hong Kong S.A.R; ${ }^{2}$ Tuen Mun Hospital, Medicine, Hong Kong, Hong Kong S.A.R

\subsection{6/lupus-2017-000215.449}

Background and aims To study the effect of disease remission on organ damage and quality of life(QOL) in Chinese patients with SLE.

Methods Adult patients who fulfilled the ACR criteria for SLE were identified and their remission status at last visits was 